\title{
Zero-a-Seis
}

\section{EDUCAÇÃO INFANTIL EM TEMPOS DE PANDEMIA: OUTROS DESAFIOS PARA OS DIREITOS, AS POLÍTICAS E AS PEDAGOGIAS DAS INFÂNCIAS}

Childhood Education in pandemic times: Other challenges for children's rights, policies and pedagogies

\author{
Cleriston Izidro dos ANJOS \\ Centro de Educação \\ Universidade Federal de Alagoas \\ Maceió, Alagoas, Brasil \\ cianjos@yahoo.com.br \\ https://orcid.org/0000-0003-1040-4909
}

\author{
Fábio Hoffmann PEREIRA \\ Campus Arapiraca \\ Universidade Federal de Alagoas \\ Arapiraca, Alagoas, Brasil \\ hoffmann@arapiraca.ufal.br \\ https://orcid.org/0000-0002-2933-2610
}

A lista completa com informações dos autores está no final do artigo

A pandemia causada pela covid-19 tem assombrado o planeta e dissipado milhares de vidas humanas. Além disso, toda as esferas do convívio e das relações sociais foram afetadas. A covid-19 ainda causa adoecimentos e mortes, sofrimento e inúmeras transformações sociais e econômicas e o cenário impôs a necessidade de isolamento social e distanciamento físico entre as pessoas para a preservação de vidas, conforme orientação a Organização Mundial da Saúde. A circulação de pessoas foi drasticamente reduzida e, em muitas localidades, medidas de distanciamento e de isolamento físico precisaram ser impostas, inclusive com confinamento obrigatório das pessoas em suas casas. No Brasil, desde o aparecimento dos primeiros $\operatorname{casos}^{1}$ de

\footnotetext{
1 O primeiro caso de transmissão interna de covid-19 foi confirmado pelo Ministério da Saúde do Brasil no dia 5 de março de 2020. As notícias indicavam que se tratava do caso de uma mulher trabalhadora, empregada doméstica, que teria contraído de sua patroa que havia ido passar férias na Europa, onde a infecção já estava em ritmo acelerado de alastramento. No cidade do Rio de Janeiro (Rio de Janeiro, Brasil), as atividades educacionais foram suspensas em 16 de março de 2020. No estado de São Paulo (Brasil) e no município de Salvador (Bahia, Brasil), a suspensão começou em 18 de março de 2020. O estado de Alagoas teve as atividades da Educação Básica e do Ensino Superior das redes públicas e privadas suspensas em 23 de março de 2020.
} 
transmissão interna da covid-19, as atividades educacionais presenciais começaram a ser suspensas. A incerteza quanto à evolução da pandemia e a suspensão de todas as atividades nas instituições educativas têm levantado uma série de questionamentos, pressões e desafios para educadores(as), gestores(as) e outros(as) profissionais da educação, bem como para as crianças e suas famílias.

De um lado, se encontram as preocupações com os vínculos construídos com as crianças desde bebês e, de outro, a impossibilidade do atendimento diário em um equipamento que, além de ser um espaço de educação e de cuidado, se constitui como lugar de proteção para muitas crianças que são vítimas de muitas mazelas em seus contextos de vida.

No campo das forças que se estabelecem socialmente, temos observado a reiterada reivindicação de famílias e grupos preocupados com possíveis prejuízos relacionados àquilo que entendem que as instituições educacionais deveriam oferecer em termos de trabalho pedagógico. Como alternativa às atividades presenciais, existem governos, em todas as esferas do Estado, implantando formas de trabalho remoto e domiciliar aos(às) servidores(as) públicos(as), incluindo profissionais da Educação Básica e do Ensino Superior. No centro dessas relações de poder, a pressão sobre docentes para que continuem a realizar o que entendem por trabalho pedagógico tem sido imensa, o que tem levado à descaracterização das formas da relação professor(a)criança e a excessos de vários lados. Em síntese, temos um cenário ainda mais intenso de ataques e ameaças aos direitos de crianças e de suas famílias, bem como aos direitos dos(as) professores(as) e demais profissionais da educação. As lutas pelos direitos, políticas e pedagogias da Educação Infantil, tema já abordado em outro dossiê (ANJOS; SANTOS; FERREIRA, 2017) se tornam ainda mais graves e intensas nesse contexto de pandemia e cenário de crise, em que a necropolítica (MBEMBE, 2016) e o desprezo pelos mais pobres (CORTINA, 2020) parecem servir de modelos para decisões políticas em diferentes esferas de nossa sociedade.

Nestas lutas, há grupos que defendem que este é um momento de trabalho com vínculos entre famílias e instituições educacionais e que o retorno seguro às atividades presenciais só é possível com a vacinação². Outros grupos apontam algumas possíveis ações que podem estar sendo realizadas nesse tempo em que as instituições estão fechadas, como forma de planejar um possível retorno presencial seguro às instituições

\footnotetext{
2 Embora as notícias que estamos acompanhando durante o percurso de fechamento deste dossiê sejam animadoras com relação às vacinas, há um discurso circulante que nega e impõe empecilhos para que a vacinação da população brasileira aconteça o mais rapidamente possível.
} 
de Educação Infantil, tendo em vista o fato de que ainda não há previsão para a vacinação de todas as crianças e suas famílias, bem como para os(as) professores(as) e demais profissionais da educação.

Este momento em que os espaços físicos das instituições educacionais estão fechados poderiam se constituir como uma oportunidade para melhorar as estruturas dos espaços públicos de Educação Infantil com as tão sonhadas reformas, mas pouco tem sido feito pelas redes educacionais nesse sentido também. A pandemia acentuou ainda mais alguns problemas já existentes em nosso sistema educacional, tal como, por exemplo, a escassez de produtos de higiene e de limpeza como materiais indispensáveis para a preservação da saúde de todos e todas desde bebês.

Estes outros desafios que a pandemia nos trouxe, evidenciam ainda mais a necessidade da criança ser considerada como uma responsabilidade de toda a sociedade. Quem olha pelas e para as crianças em uma situação de emergência e em um cenário de crise? A partir deste questionamento, esse dossiê pretendeu reunir, debater e compartilhar pesquisas e reflexões sobre a Educação Infantil em tempos de pandemia a partir de olhares sobre os princípios e os fundamentos sobre os quais a Educação Infantil brasileira é organizada e considerando os diversos problemas agravados pela pandemia, que envolvem, dentre outros fatores, a ampliação e aceleração dos processos de mercantilização da Educação.

Como pesquisadores e pesquisadoras ligados(as) ao Grupo de Estudos e Pesquisas em Pedagogias e Culturas Infantis (GEPPECI/CNPq/UFAL, Brasil), temos observado que os excessos que vêm sendo cometidos acabam por desrespeitar direitos das crianças desde bebês, das famílias, de seus professores(as) e demais profissionais da educação. Docentes da Educação Infantil, gestores(as), equipes técnicas das redes, estudantes e docentes universitários, nos trazem questionamentos sobre as suspensões dos serviços públicos para as crianças desde o início da pandemia, procurando ajuda e orientação. Parece que, de repente, uma parcela da população se dá conta de que as crianças existem e suas vozes precisam ser ouvidas. Há, ao mesmo tempo, uma preocupação e um incômodo no ar: se as crianças não podem frequentar as instituições de Educação Infantil, como lidar com essa realidade?

A pandemia também escancarou outros problemas, tais como, por exemplo, as desigualdades de gênero e de raça. Temos ouvido relatos, inclusive das mulheres professoras e pesquisadoras com as quais convivemos, que sinalizam as dificuldades de ser mulher, mãe e trabalhadora em uma sociedade machista e misógina como a nossa (SOARES; CIDADE; CARDOSO, 2020). A enorme quantidade de crianças negras 
e pobres mortas por negligência do Estado em relação à assistência social e a políticas de emprego e de distribuição e manutenção de renda é assustadora (PUENTE, 2021).

O GEPPECI foi um dos primeiros grupos de pesquisa a desenvolver atividades online sobre "Infâncias, educação e pandemia", por meio do nosso perfil na rede social Instagram ${ }^{\circledR}$, no formato de transmissão ao vivo e que ficaram conhecidas como Lives do GEPPECI $^{3}$, de modo a compartilhar nossos estudos, inquietações e a debater com outros(as) educadores(as) e pesquisadores(as) das infâncias. Desde o início da pandemia, promovemos debates sobre Infâncias e Educação Infantil para pensar esse cenário de caos trazido pela covid-19 e por nosso contexto político e social, contando com participação de muitos(as) colaboradores(as). Organizamos, também o Webnário "Infâncias e Educação Infantil em tempos de pandemia", com quatro sessões de debate entre os dias 18 de junho e 01 de julho de 2020, transmitido e disponível no YouTube ${ }^{\circledR}$ (GEPPECI, 2020). Além de formativas e reflexivas, essas atividades apontam para uma necessidade do nosso grupo de pesquisa de contribuir com o debate nesse cenário, nos unindo a outros grupos e pessoas de modo a exercer o compromisso social da universidade pública, gratuita, laica e de qualidade com o processo de transformação da sociedade.

Nesse sentido, este dossiê tem o objetivo de reunir, debater e compartilhar pesquisas e reflexões sobre a educação das crianças pequenas desde bebês em tempos de pandemia a partir dos princípios e dos fundamentos sobre os quais a Educação Infantil brasileira é organizada e considerando os diversos problemas agravados pela presença da covid-19, que envolvem, dentre outros fatores, a ampliação e aceleração dos processos de mercantilização da Educação. Alguns artigos são frutos diretos dos nossos debates no Instagram $^{\circledR}$ e no YouTube ${ }^{\circledR}$, mas também há diversas outras contribuições.

A Lei de Diretrizes e Bases da Educação Nacional (BRASIL, 1996), em seu artigo 29, estabelece que a finalidade da Educação Infantil é "o desenvolvimento integral da criança de até 5 (cinco) anos, em seus aspectos físico, psicológico, intelectual e social, complementando a ação da família e da comunidade". Para nortear as atividades-fim dessa etapa da Educação Básica, as Diretrizes Curriculares Nacionais para a Educação Infantil (BRASIL, 2009), indicam princípios éticos, políticos e estéticos e afirmam que práticas pedagógicas devem possibilitar experiências diversas às crianças desde bebês, tendo as interações e a brincadeira como eixos do currículo. Esses princípios são aqueles

\footnotetext{
3 Para saber mais, acesse o perfil @geppeci na rede social Instagram ${ }^{\circledR}$.
} 
que caracterizam o desenvolvimento do trabalho desta primeira etapa da Educação Básica. Eles somente se concretizam a partir de experiências significativas de interações das crianças com outras crianças, com os(as) adultos(as), com os espaços e os materiais organizados intencionalmente para possibilitar experiências desafiadoras que possibilitam múltiplas aprendizagens $e$, consequentemente, 0 desenvolvimento integral.

A suspensão das atividades presenciais com as crianças a partir da segunda quinzena do mês de março de 2020 impossibilitou os encontros que são finalidades, princípios, fundamentos, eixos e práticas educativas que caracterizam a Educação Infantil. Nesse contexto, no mesmo mês, os processos de mercantilização que tornam a Educação um produto como outro qualquer, encontraram mais uma brecha para adentrar na Educação Básica e no Ensino Superior: a ampliação da defesa do uso indiscriminado de tecnologias digitais, plataformas e materiais didático-pedagógicos online; com a justificativa de que estamos impossibilitados de realizar atividades educativas presenciais. Se, por um lado, o distanciamento físico é necessário e as tecnologias digitais nos permitem realizar muitas tarefas, por outro, é preciso uma reflexão a respeito dos usos e abusos desses recursos e das implicações para a formação humana e humanizadora.

O texto de Fabiana Canavieira, neste dossiê, discute belissimamente a formação humana e o sentido da vida. Para ela, "[...] a educação não devia se ocupar apenas em ensinar o valor da vida de forma individualizada [...] que nada tem a ver com conhecimento ou aprendizagem, não é a apropriação de algo, mas sim uma ética" (CANAVIEIRA, 2021, p. 28).

Quando observamos, ainda em março de 2020, a preocupação com a suspensão das atividades presenciais, percebe-se que a Educação deixa de ser um valor de vida e assume o valor econômico: as atividades educacionais assumem a materialidade econômica. Esse movimento foi observado inicialmente em instituições privadas. A pressão de familiares, clientes que pagam por "aulas" foi imensa e as instituições viramse obrigadas a planejar e iniciar formas de atendimento não-presencial, com uso de tecnologias digitais. Rapidamente, o ensino remoto alcançou todos os níveis da Educação Básica e do Ensino Superior. Em seguida, essa lógica mercadológica chegou ao setor público. Alguns artigos desta coletânea discutem formas pelas quais o ensino remoto contribui para aprofundar as desigualdades sociais. Ivone Garcia Barbosa e Marcos Antônio Soares perceberam que "famílias e professores ficaram divididos quanto 
à defesa desse novo formato de atendimento e o retorno às atividades presenciais" (BARBOSA; SOARES, 2021, p. 45-46).

Por meio de conversas informais com professoras de Educação Infantil, Míghian Danae Ferreira Nunes afirma que elas são descrentes "quanto à efetividade das atividades virtuais que muitas secretarias municipais decidiram fazer acontecer em redes sociais que não foram criadas para fins educacionais pertinentes à interação das famílias e à aprendizagem das crianças" (NUNES, 2021, p. 64). A autora propõe alguns caminhos possíveis para uma Educação Infantil antirracista num contexto de construção de uma nova possibilidade pós-pandemia. Maria Tereza Goudard Tavares, Fabiana Nery de Lima Pessanha e Nayara Alves Macedo ponderam que apesar de promover alguma interação o ensino remoto não atende "plenamente aos princípios da Educação Infantil como contexto de vida coletiva, além de evidenciarem lacunas referentes às condições heterogêneas de acesso a essas plataformas virtuais, ampliando as desigualdades sociais" (TAVARES; PESSANHA; MACEDO, 2021, p. 94).

Adelaide Alves Dias, Isabelle Sercundes Santos e Adams Ricardo Pereira de Abreu alertam que "a regulamentação de atividades não-presenciais para crianças, inclusive, para as da Educação Infantil, fez com que emergissem algumas dissonâncias, uma vez que alguns grupos de crianças ficaram em desvantagem diante desse novo contexto" (DIAS; SANTOS; ABREU, 2021, p. 107) e trazem uma discussão sobre o atendimento às crianças com transtornos do espectro autista e as dificuldades enfrentadas para execução de Planos Educacionais Individualizados.

No artigo sobre Educação Infantil e tecnologias digitais, Cleriston Izidro dos Anjos e Deise Juliana Francisco abordam que se, por um lado, "as atividades remotas ferem os princípios e especificidades da Educação Infantil, por outro, em alguns contextos, as TDIC podem se constituir como possíveis recursos de comunicação e manutenção de vínculos" entre as instituições e as crianças e suas famílias (ANJOS; FRANCISCO, 2021, p. 141). O autor e a autora alertam que, no entanto, "essa discussão sobre TDIC na Educação Infantil escancara ainda mais a necessidade de políticas integradas de atendimento às infâncias e do fato de que toda a sociedade precisa assumir suas responsabilidades com as crianças" (ANJOS; FRANCISCO, 2021, p. 141-142).

No segundo semestre de 2020 intensificaram-se as discussões sobre a necessidade das políticas integradas ou intersetoriais de atendimento às crianças desde bebês e como alternativa para que a Educação Infantil, como parte desse sistema integrado, possa continuar desempenhando suas funções sociais. No artigo de Silvia Helena Vieira Cruz, Cristiane Amorim Martins e Rosimeire Costa de Andrade Cruz, as 
autoras defendem que uma das demandas impostas pela pandemia para a Educação Infantil é o planejamento de políticas integradas por ações intersetoriais. As autoras chamam a atenção para o respeito aos direitos não apenas das crianças, mas também de suas famílias trabalhadoras e das/dos profissionais da educação (CRUZ; MARTINS; CRUZ, 2021).

Sobre o tema dos direitos, destacamos dois documentos publicados em 2020 e que podem ajudar o poder público no planejamento de ações. Os documentos Para um retorno à escola e à creche que respeite os direitos fundamentais de crianças, famílias e educadores (CAMPOS et. al., 2020) e o Caderno de Direitos - Retorno à creche e à escola: Direitos das crianças, suas famílias e suas/seus educadoras/es, elaborado pela Frente Nordeste Criança (MELLO; NEGREIROS; ANJOS, 2020) são de suma importância, ao lado de boletins e protocolos de higiene e saúde emitidos por instituições como a Fundação Oswaldo $\mathrm{Cruz}^{4}$ e pela Campanha Nacional pelo Direito à Educação ${ }^{5}$. Destacam-se, ainda, as reflexões provenientes de diversas lives produzidas por diversos grupos de pesquisas, movimentos sociais e associações em defesa das crianças e suas infâncias e da Educação Infantil (SANTOS; SILVA; FARIA, 2020), dentre outros materiais.

Ângela Maria Scalabrin Coutinho e Cintia Cardoso apresentam uma pesquisa com famílias que possuem bebês e apontam que a demanda do cuidado é central na sustentabilidade da vida e "a organização de uma sociedade passa pelas dimensões mais amplas do cuidar" (COUTINHO; CARDOSO, 2021, p. 187). As autoras indicam que o isolamento físico trouxe sérias consequências para as famílias das camadas empobrecidas da população, sobretudo famílias negras, em relação à diminuição da renda e também um aumento de trabalho para as mulheres, que têm sido as responsáveis pelo cuidado de bebês e das crianças pequenas.

Estamos convencidos de que as instituições de Educação Infantil têm uma importância estratégica no combate às desigualdades e no sistema de proteção às crianças pequenas desde bebês. Instituições educativas são a presença do Estado no cotidiano das famílias brasileiras. Nesses lugares, as famílias que possuem crianças encontram profissionais que podem lhes orientar quase todos os dias, contribuindo para

\footnotetext{
${ }^{4}$ Fundação Oswaldo Cruz criou o Observatório COVID-19. Os documentos publicados pela instituição podem ser acessados em https://portal.fiocruz.br/observatorio-covid-19.

5 A Campanha Nacional pelo Direito à Educação publicou uma série de documentos com o objetivo de oferecer informações "checadas, comprovadas e acessíveis sobre como cidadãos ligados à educação podem agir, cobrar, e trabalhar pela proteção de todos de maneira colaborativa". Os Guias COVID-19 estão disponíveis em: https://campanha.org.br/covid-19/.
} 
apontar caminhos para que elas conheçam e cheguem até os programas de assistência social, trabalho e renda, por exemplo. Não defendemos que profissionais da educação devam assumir tarefas que competem à outras profissões, mas é fundamental que conheçam os caminhos para que as crianças e suas famílias lutem por seus direitos outros (saúde, educação, trabalho e renda, moradia, esporte, cultura, lazer etc).

A postura do presidente em exercício, Jair Bolsonaro, diante dos eventos da pandemia ao longo do ano de 2020, foi de abstenção das suas responsabilidades e de negação do conhecimento científico produzido com seriedade por muitos(as) pesquisadores(as) que continuam trabalhando ao lado de profissionais de diversas áreas e linhas de frente desse imenso Brasil, como forma de amenizar o sofrimento da população brasileira. Sandra Caponi (2020) lembra que o negacionismo fora adotado como uma promessa, "já na campanha eleitoral, com seu desprezo pelas universidades, pela pesquisa científica, pelos direitos das populações vulneráveis, pelas comunidades indígenas, LGBT, populações de rua, mulheres em situação de violência etc." (CAPONI, 2020, p. 210). Entre "defender a vida" e "defender a economia", como anunciado nas mídias diversas desse país, não temos visto nem uma coisa, nem outra.

Grande parte dos artigos nesta coletânea, de uma forma ou de outra, abordam o descaso com o qual as brasileirinhas e os brasileirinhos têm sido tratados como parte de um projeto necropolítico neoliberal (MBEMBE, 2016) e de aversão aos mais pobres (CORTINA, 2020). O texto de Joedson Brito dos Santos e Maria Aparecida Antero Correia evidenciam as diferenças com que a Educação Infantil foi tratada no Brasil e na Itália. No contexto italiano, país em que a covid-19 alastrou-se com maior intensidade nos primeiros meses de 2020 após erros de avaliação, o processo de lockdown "foi controlado pelo governo central, mas articulado com os presidentes das regiões" (SANTOS; CORREIA, 2021, p. 214). No Brasil, que "tinha a seu favor o conhecimento das experiências e medidas políticas, econômicas e sociais, tomadas por diversos países que já enfrentavam a pandemia" (p. 214), "o Governo Federal optou por medidas isoladas, [...] sem efetividade e alcance da população" (p. 214). O autor e a autora contam que o governo brasileiro "defendeu ações mais voltadas para o campo do capital financeiro e dos empresários e uma política econômica de austeridade" (p. 214), sem defesa do isolamento físico e social e transferindo a responsabilidade por medidas preventivas e de combate - como, por exemplo, o lockdown -, para os Estados e municípios.

Roselane Campos e Zeneide Durli apresentam as ações normativas que impactam a Educação Infantil no contexto da pandemia. As autoras ressaltam que a elaboração 
de ações político-governamentais se deram em "interlocução estabelecida com grupos empresariais da educação representados por fundações, organizações de tipo filantrópico, cujos estudos são usados para a elaboração do 'diagnóstico da educação básica'" (CAMPOS; DURLI, 2021, p. 229). As autoras destacam que grande parte dos documentos orientadores e resoluções do Conselho Nacional de Educação fazem alusão aos "direitos de aprendizagem" listados na Base Nacional Comum Curricular - BNCC (BRASIL, 2017) e concluem, entre outras questões, que as atividades não-presenciais da Educação Infantil ficaram subordinadas aos objetivos, habilidades e competências que orientam a BNCC, parecendo que chega-se "a definir a finalidade da educação como cumprimento da BNCC" (CAMPOS; DURLI, 2021, p. 236).

Como exemplos das discussões presentes, alguns contextos específicos são apresentados neste dossiê. No município de Humaitá, localizado na Região Amazônica, Brasil, marcado pela presença de áreas indígenas e pela exploração da madeira, houve a preocupação da Secretaria Municipal de Educação em instituir orientações metodológicas para o desenvolvimento de atividades didáticas durante a pandemia. No entanto, Zilda Glaucia Elias Franco, Eulina Maria Leite Nogueira e Welton de Araújo Prata (2021) afirmam que as/os profissionais da Educação não tiveram formação e apoio para que pudessem desenvolver atividades remotas. Em uma região onde a população tem ausência de tantas coisas, as autoras e autor defendem que "o acesso à internet é um direito fundamental, a exemplo dos direitos ainda não assegurados pela política pública municipal local, assim como a água potável, a rede de esgoto, a energia e o transporte" (FRANCO; NOGUEIRA; PRATA, 2021, p. 262). Essa realidade, apesar de pontual, infelizmente, não é um caso isolado.

Mudanças nas relações sociais e nas formas de sociabilidade foram impostas pelo contexto de pandemia. Nisso, a formação de professores é uma problemática a ser seriamente debatida. Elisabete Xavier Gomes (2021) levanta uma questão importante: as professoras e os professores são formados com foco no ensino, não na aprendizagem e esta constatação indica uma multiplicidade de implicações para a educação das crianças. O texto de Juliano Silveira (2021) apresenta o relato de experiência do professor que precisou aprender a utilizar recursos e ferramentas tecnológicas com as quais não estava acostumado e a desenvolver formas de sociabilidade com crianças e suas famílias. É um relato de experiência que mostra que a existência de ser professor é, também, resistência.

Em tempos de pandemia, necropolítica e aversão aos mais pobres, os retrocessos têm sido imensos. Por isso, formas de resistência precisam ser construídas, ampliadas 
e fortalecidas com vistas ao enfrentamento das injustiças agravadas com o desgoverno em curso no Brasil. A atuação dos movimentos sociais como formas de provocar discussões, problematizar as políticas públicas e as ações pedagógicas desenvolvidas, bem como pressionar os governos em defesa das crianças e da Educação Infantil passa a ter uma importância estratégica no enfrentamento à pandemia, mas também no combate ao aprofundamento das desigualdades. Fábio Hoffmann Pereira apresenta um levantamento das ações dos fóruns estaduais de Educação Infantil vinculados ao Movimento Interfóruns de Educação Infantil do Brasil (MIEIB). A atuação dos movimentos sociais mostra que "se o isolamento na situação de pandemia foi físico, evidentemente ele não foi social" (PEREIRA, 2021, p. 311).

Na seção "Resenhas", este dossiê contou, ainda, com as contribuições de Isabella Brunini Simões Padula (2021) e Nélia Aparecida da Silva Cavalcante (2021), que apresentam publicações importantes em tempos de cerceamento de liberdades, de direitos e de resistência.

O cenário de pandemia causado pela covid-19 tem trazido uma série de inquietações e desafios para as instituições e para o campo da Educação Infantil. 0 contexto de isolamento físico torna visíveis desigualdades sociais das crianças pequenas desde bebês que frequentam creches e pré-escolas brasileiras e coloca em debate a função social dessas instituições, da docência e do currículo.

Diante dessa situação, observa-se o aparecimento de um conjunto de propostas de atividades não-presenciais como uma alternativa às experiências que eram proporcionadas pelas creches e pré-escolas, geralmente apresentadas para responder às cobranças que recaem sobre as instituições, advindas da angústia das famílias com a suspensão da educação presencial para suas crianças desde bebês.

Vemos, por um lado, uma série de posicionamentos de organizações da sociedade civil que lutam pelos direitos das crianças e dos movimentos sociais que são contrários a qualquer forma de educação não-presencial. Por outro, nos deparamos com as orientações no âmbito das políticas governamentais de educação, advindas de instâncias de consulta, deliberação e execução do poder público que engendram possíveis concepções mercantilizadas da educação que acabam sendo incompatíveis com o que preconizam os próprios documentos oficiais.

Este dossiê pretende oferecer elementos para reflexão e discussão sobre a importância dessas e outras questões que afetam diretamente a educação das crianças pequenas desde bebês, tais como: a formação docente para a Educação Infantil e o papel das universidades, as políticas públicas de educação e dos direitos das crianças, 
as desigualdades sociais que afetam crianças e profissionais da educação, além da questão da relação com a cidade e os movimentos sociais.

Os diálogos que o GEPPECI tem estabelecido com outros(as) pesquisadores(as) tem sido tão rico que, dessas reflexões sobre "Infâncias, educação e pandemia" nasceram dois dossiês, sendo o primeiro lançado em dezembro de 2020, sob organização de Solange Estanislau dos Santos e Marina Rebeca de Oliveira Saraiva intitulado "As crianças e suas infâncias em tempos de pandemia" (SANTOS; SARAIVA, 2020), cujo volume contou com artigos e contribuições em formato de depoimento de Susanna Mantovani e Daniela Aparecida Vieira (2020), Teresa Sarmento e Daniela Silva (2020), Nanci Helena Rebouças Franco e Maria Patricia Figueiredo Soares (2020), Márcia Aparecida Gobbi, Juliana Diamente Pito, Simone Maria Magalhães Meleán (2020), Marcia Lucia Anacleto de Souza (2020), Márcia Mara Ramos, Valter de Jesus Leite e Janaína Ribeiro de Rezende (2020), Mirian Lange Noal e Denise Silva (2020), Célia Ratusniak, Ivanilde dos Santos Mafra e Vanderlete Pereira da Silva (2020), Fernanda Cristina de Souza (2020), Elina Elias Macedo (2020), Márcia Buss-Simão e Juliana Schumacker Lessa (2020). Contou, também, com contribuições na seção "outras linguagens" com os trabalhos de Andréia Regina de Oliveira Camargo e César Leite (2020) e Alana Barros Santos (2020) e na seção "resenhas" que foram redigidas por Wilma Rigolon (2020), Vivian Colella Esteves (2020) e Fabiana Oliveira Canavieira (2020).

Gostaríamos de agradecer imensamente a todos(as) os(as) convidados(as) que participaram das Lives do GEPPECI, que aconteceram de abril a agosto de 2020, e do Webnário "Infâncias e Educação Infantil em tempos de pandemia". Esta coletânea é fruto dessas atividades desenvolvidas no âmbito da Universidade Federal de Alagoas (UFAL, Brasil). Agradecemos ao público que vinha participando conosco e que agora pode ler algumas da reflexões sobre as quais conversamos no formato de transmissão ao vivo e outras que chegam agora, registradas no formato de texto acadêmico. Agradecemos imensamente à Revista Zero-a-Seis, pela acolhida e compromisso com a divulgação do conhecimento científico de modo gratuito, aberto e livre e à Profa. Dra. Marcia Buss-Simão (UFSC, Brasil), pela partilha sempre solidária, afetiva e séria. Convidamos a todos(as) os(as) leitores(as) a navegarem pelos artigos, relato de experiências e a conhecerem os livros indicados nas duas resenhas. Boa leitura! Que 2021 seja melhor para todas, todos e todes! 


\section{REFERÊNCIAS}

ANJOS, Cleriston Izidro dos; FRANCISCO, Deise Juliana. Educação Infantil e Tecnologias Digitais: reflexões em tempos de pandemia. Zero-a-Seis, Florianópolis, v. 23, n. Especial, p. 125-146, jan./jan., 2021. Disponível em:

https://doi.org/10.5007/1980-4512.2021.e79007.

ANJOS, Cleriston Izidro dos; SANTOS, Solange Estanislau dos; FERREIRA, Fernando Ilídio. As lutas pela Educação Infantil: políticas, direitos e pedagogias. Zero-a-Seis, Florianópolis, v. 19, n. 36 p.156-165, jul-dez 2017. Disponível em:

https://doi.org/10.5007/\%25x

BARBOSA, Ivone Garcia; SOARES, Marcos Antônio. Educação Infantil e pobreza infantil em tempos de pandemia no Brasil: existirá um "novo normal"? Zero-a-Seis, Florianópolis, v. 23, n. Especial, p. 35-57, jan./jan., 2021. Universidade Federal de Santa Catarina. Disponível em: https://doi.org/10.5007/1980-4512.2021.e79044.

BRASIL. Conselho Nacional de Educação. Câmara de Educação Básica. Resolução n. 05, de 17 de dezembro de 2009. Fixa as Diretrizes Curriculares Nacionais para a Educação Infantil. Disponível em:

http://portal.mec.gov.br/index.php?option=com docman\&view=download\&alias=229 8-rceb005-09\&category slug=dezembro-2009-pdf\&Itemid=30192.

BRASIL. Lei n. 9.394, de 20 de dezembro de 1996. Estabelece as diretrizes e bases da educação nacional. Disponível em:

http://www.planalto.gov.br/ccivil 03/leis/l9394.htm.

BRASIL. Ministério da Educação. Base Nacional Comum Curricular. Brasília: MEC, 2017. Disponível em:

http://basenacionalcomum.mec.gov.br/images/BNCC EI EF 110518 versaofinal site .pdf.

BUSS-SIMÃO, Márcia, LESSA, Juliana Schumacker. Um olhar para o(s) corpo(s) das crianças em tempos de pandemia. Zero-a-Seis, Florianópolis, v. 22, n. Especial, p. 1420-1445, dez./dez., 2020. Disponível em: https://doi.org/10.5007/1980-

4512.2020v22nespp1420.

CAMARGO, Andréia Regina de Oliveira, LEITE, César. Desaprender a cada tempo em tempos pandêmicos: crianças, artes e outros contágios. Zero-a-Seis, Florianópolis,v. 22, n. Especial, p. 1446-1464, dez./dez., 2020. Disponível em:

https://doi.org/10.5007/1980-4512.2020v22nespp1446.

CAMPOS, Maria Malta (coord). Para um retorno à escola e à creche que respeite os direitos fundamentais de crianças, famílias e educadores. Brasil: ANPEd.

Associação Nacional de Pesquisa e Pós-Graduação em Educação, 2020. Disponível em: https://anped.org.br/sites/default/files/images/para um retorno a escola e a crech e-2.pdf.

CAMPOS, Roselane; DURLI, Zeneide. Infância confinada: liturgias de escolarização e privatização da Educação Infantil. Zero-a-Seis, Florianópolis, v. 23, n. Especial, p. 
221-243, jan./jan., 2021. Disponível em: https://doi.org/10.5007/19804512.2021.e79059.

CANAVIEIRA, Fabiana Oliveira. "A vida não é útil": sonhar e suspender o céu. Zero-aSeis, Florianópolis, v. 22, n. Especial, p. 1530-1537, dez./dez., 2020. Disponível em: https://doi.org/10.5007/1980-4512.2020v22nespp1530.

CANAVIEIRA, Fabiana Oliveira. Formação humana e o sentido da vida: quais pedagogias? Zero-a-Seis, Florianópolis, v. 23, n. Especial, p. 21-34, jan./jan., 2021. Disponível em: https://doi.org/10.5007/1980-4512.2021.e78992.

CAPONI, Sandra. Covid-19 no Brasil: entre o negacionismo e a razão neoliberal. Estudos Avançados, São Paulo, v. 34, n. 99, p. 209-224, ago. 2020.bDisponível em: http://dx.doi.org/10.1590/s0103-4014.2020.3499.013.

CAVACANTE, Nélia Aparecida da Silva Cavalcante. Racismo e infância: intersecções de raça, classe social, gênero e idade na creche. Zero-a-Seis, Florianópolis, v. 23, n. Especial, p. 342-352, jan./jan., 2021. Disponível em: https://doi.org/10.5007/19804512.2021.e78534

CORTINA, Adela. Aporofobia, a aversão ao pobre: um desafio para a democracia. São Paulo: Editora Contracorrente, 2020.

COUTINHO, Ângela Maria Scalabin; CARDOSO, Cintia. A educação e o cuidado dos bebês na pandemia: uma análise a partir das relações geracionais, raciais e de gênero. Zero-a-Seis, Florianópolis, v. 23, n. Especial, p. 175-194, jan./jan., 2021. Disponível em: https://doi.org/10.5007/1980-4512.2021.e79001.

CRUZ, Silvia Helena Vieira; MARTINS, Cristiane Amorim; CRUZ, Rosimeire Costa de Andrade. A Educação Infantil e as demandas postas pela pandemia: intersetorialidade, identidade e condições para o retorno às atividades presenciais. Zero-a-Seis, Florianópolis, v. 23, n. Especial, p. 147-174, jan./jan., 2021. Disponível em: https://doi.org/10.5007/1980-4512.2021.e79003.

DIAS, Adelaide Alves; SANTOS, Isabelle Sercundes; ABREU, Adams Ricardo Pereira de. Crianças com transtorno do espectro autista em tempos de pandemia: contextos de inclusão/exclusão na Educação Infantil. Zero-a-Seis, Florianópolis, v. 23, n. Especial, p. 101-124, jan./jan., 2021. Disponível em: https://doi.org/10.5007/19804512.2021.e79005.

ESTEVES, Vivian Colella. Um alerta feminista para a educação das crianças pequenas: contra os "rachismos" na infância. Zero-a-Seis, Florianópolis, v. 22, n. Especial, p. 1515-1529, dez./dez., 2020. Disponível em: https://doi.org/10.5007/19804512.2020v22nespp1515.

FRANCO, Nanci Helena Reboucas; SOARES, Maria Patricia Figueiredo. "Um jeito negro de ser e viver": (re) inventando a vida no contexto da pandemia da covid-19 - o que dizem as crianças negras e suas mães. Zero-a-Seis, Florianópolis, v. 22, n. Especial, p. 1229-1254, dez./dez., 2020. Disponível em: https://doi.org/10.5007/19804512.2020v22nespp1229. 
FRANCO, Zilda Glaucia Elias; NOGUEIRA, Eulina Maria Leite; PRATA, Welton de Araújo. Educação Infantil no contexto amazônico: experiências em tempos de pandemia. Zero-a-Seis, Florianópolis, v. 23, n. Especial, p. 244-268, jan./jan., 2021. Disponível em: https://doi.org/10.5007/1980-4512.2021.e78988.

GEPPECI. Grupo de Estudos e Pesquisas e Pedagogias e Culturas Infantis. Webnário Infâncias e Educação Infantil em Tempos de Pandemia. Maceió (Transmissão online): Universidade Federal de Alagoas, 18 jun. a 01 jul. 2020. Disponível em: https://www.youtube.com/channel/UC78d98Iz2-iZa0v1W3qSnoQ.

GOBBI, Márcia Aparecida; PITO, Juliana Diamente; MELEÁN, Simone Maria Magalhães. Crianças e mulheres e nós-nada: reflexões a partir das vidas em despejo no acampamento Campo Grande do MST. Zero-a-Seis, Florianópolis, v. 22, n. Especial, p. 1255-1280, dez./dez., 2020. Disponível em: https://doi.org/10.5007/19804512.2020v22nespp1255.

GOMES, Elisabete Xavier. Pedagogia da presença na formação de educadoras/es de infância: perspectivas sobre as suas (im)potências no âmbito da pandemia. Zero-aSeis, Florianópolis, v. 23, n. Especial, p. 269-290, jan./jan., 2021. Disponível em: https://doi.org/10.5007/1980-4512.2021.e79039.

MACEDO, Elina Elias. Desigualdade e pandemia nas vidas das brasileirinhas e dos brasileirinhos. Zero-a-Seis, Florianópolis, v. 22, n. Especial, p. 1404-1419, dez./dez., 2020. Disponível em: https://doi.org/10.5007/1980-4512.2020v22nespp1404.

MANTOVANI, Susanna; VIEIRA, Daniela Aparecida. Depoimento sobre o fechamento das creches na itália: como resistir à incerteza em tempos de pandemia? Zero-aSeis, Florianópolis, v. 22, n. Especial, p. 1197-1205, dez./dez., 2020. Disponível em: https://doi.org/10.5007/1980-4512.

MBEMBE, Achile. Necropolítica. Arte e Ensaios, Rio de Janeiro, n. 32, v. 2, 2016. Disponível: https://revistas.ufrj.br/index.php/ae/article/view/8993/7169.

MELLO, Ana Maria Araújo; NEGREIROS, Fauston; ANJOS, Cleriston Izidro dos.

Caderno de Direitos - Retorno à creche e à escola: Direitos das crianças, suas famílias e suas/seus educadoras/es - gestoras/es, professoras/es e funcionárias/os. Piauí: FRENTE NORDESTE CRIANÇA/EDUFPI, 2020. 34pp. 17fls. (Círculo Temático Violência e Direitos Humanos - Subgrupo 8 - Políticas Públicas). Disponível em: https://www.ufpi.br/arquivos download/arquivos/Caderno Direitos EDULPI com ISBN20200725103619.pdf

NOAL, Mirian Lange; SILVA, Denise. Crianças pequenas terena: reencontros ancestrais em tempos de pandemia. Zero-a-Seis, Florianópolis, v. 22, n. Especial, p. 1332-1363, dez./dez., 2020. Disponível em: https://doi.org/10.5007/19804512.2020v22nespp1332.

NUNES, Míghian Danae Ferraira. Educação antirracista para crianças pequenas: ideias para começar um novo mundo. Zero-a-Seis, Florianópolis, v. 23, n. Especial, p. 5876, jan./jan., 2021. Disponível em: https://doi.org/10.5007/1980-4512.2021.e79002. 
PADULA, Isabella Brunini Simões. Construindo movimentos: uma conversa em tempos de pandemia. Zero-a-Seis, Florianópolis, v. 23, n. Especial, p. 333-341, jan./jan., 2021. Disponível em: https://doi.org/10.5007/1980-4512.2021.e78398.

PEREIRA, Fábio Hoffmann. Atuação dos fóruns de defesa da Educação Infantil em tempos de pandemia. Zero-a-Seis, Florianópolis, v. 23, n. Especial, p. 291-315, jan./jan., 2021. Disponível em: https://doi.org/10.5007/1980-4512.2021.e78977.

PUENTE, Beatriz. Número de crianças baleadas na Região Metropolitana do Rio cresceu 267\% em 2020. CNN Brasil, 10 de janeiro de 2021. Disponível em: https://www.cnnbrasil.com.br/nacional/2021/01/10/numero-de-criancas-baleadas-naregiao-metropolitana-do-rio-cresceu-267-em-2020.

RAMOS, Márcia Mara; LEITE, Valter de Jesus; REZENDE, Janaína Ribeiro de. As crianças sem terrinha e o enfrentamento à pandemia de covid-19: como brincar, sorrir e lutar nesse contexto? Zero-a-Seis, Florianópolis, v. 22, n. Especial, p. 13051331, dez./dez., 2020. Disponível em: https://doi.org/10.5007/19804512.2020v22nespp1305.

RATUSNIAK, Célia; MAFRA, Ivanilde dos Santos; SILVA, Vanderlete Pereira da. A travessia das infâncias no Amazonas no contexto de distanciamento social. Zero-aSeis, Florianópolis, v. 22, n. Especial, p. 1364-1382, dez./dez., 2020. Disponível em: https://doi.org/10.5007/1980-4512.2020v22nespp1364.

RIGOLON, Wilma. Pedagogia e Infâncias: um estado de alerta. Zero-a-Seis, Florianópolis, v. 22, n. Especial, p. 1504-1514, dez./dez., 2020. Disponível em: https://doi.org/10.5007/1980-4512.2020v22nespp1504.

SANTOS, Alana Barros. Retratos da pandemia no bairro da levada: infância e crise em um "bairro de periferia". Zero-a-Seis, Florianópolis, v. 22, n. Especial, p. 1465-1477, dez./dez., 2020. Disponível em: https://doi.org/10.5007/1980-

4512.2020v22nespp1465.

SANTOS, Natália Francisca Cardia dos; SILVA, Adriana Alves da; FARIA, Ana Lúcia Goulart de. Resistir para/com a infância continuar a existir: transcrição de 21 lives sobre infâncias e Educação Infantil na pandemia de Covid-19. Zero-a-Seis, Florianópolis, v. 22, n. 42, p. 852-1174, jul./dez., 2020. Disponível em: http://dx.doi.org/10.5007/1980-4512.2020v22n42p726.

SANTOS, Joedson Brito dos; CORREIA, Maria Aparecida Antero. Políticas públicas de Educação Infantil em contexto de pandemia: considerações a partir da realidade de Brasil e Itália. Zero-a-Seis, Florianópolis, v. 23, n. Especial, p. 195-220, jan./jan., 2021. Disponível em: https://doi.org/10.5007/1980-4512.2021.e79038.

SANTOS, Solange Estanislau dos; SARAIVA, Marina Rebeca de Oliveira. O ano que não tem fim: as crianças e suas infâncias em tempos de pandemia. Zero-a-Seis, Florianópolis, v. 22, n. Especial, p. 1177-1187, dez./dez., 2020. Disponível em: https://doi.org/10.5007/1980-4512.2020v22nespp1177.

SARMENTO, Teresa; SILVA, Daniela. "Queo a minha Shela, queo os amigos": refletir o isolamento social de bebés em tempos de pandemia, na base de uma experiência vivida em Portugal. Zero-a-Seis, Florianópolis, v. 22, n. Especial, p. 1206-1228, 
dez./dez., 2020. Disponível em: https://doi.org/10.5007/19804512.2020v22nespp1206.

SILVEIRA, Juliano. O teletrabalho coletivo durante a pandemia da covid-19: um relato de experiência na Educação Infantil de Florianópolis. Zero-a-Seis, Florianópolis, v. 23, n. Especial, p. 316-332, jan./jan., 2021. Disponível em: https://doi.org/10.5007/1980-4512.2021.e76802.

SOARES, Ana Carolina Eiras Coelho; CIDADE, Camilla de Almeida Santos; CARDOSO, Vanessa Clemente. Maternidades plurais: Os diferentes relatos aventuras e oceanos das mães cientistas na pandemia. Belford Roxo: Bindi, 2020. Disponível em: https://docs.google.com/forms/d/e/1FAIpQLSdGQ0blpHqmKVLyEbecwRh44hWQB873 Mh UxQGYysA39iSzQQ/viewform.

SOUZA, Fernanda Cristina de. É preciso erguer a voz: diálogos sobre movimentos sociais, infâncias e pandemia. Zero-a-Seis, Florianópolis, v. 22, n. Especial, p. 13831403, dez./dez., 2020. Disponível em: https://doi.org/10.5007/19804512.2020v22nespp1383.

SOUZA, Marcia Lucia Anacleto de. (In)visíveis? crianças quilombolas e a necropolítica da infância no Brasil. Zero-a-Seis, Florianópolis, v. 22, n. Especial, p. 1281-1304, dez./dez., 2020. Disponível em: https://doi.org/10.5007/19804512.2020v22nespp1281.

TAVARES, Maria Tereza Goudard; PESSANHA, Fabiana Nery de Lima; MACEDO, Nayara Alves. Impactos da pandemia de covid-19 na Educação Infantil em São Gonçalo/RJ. Zero-a-Seis, Florianópolis, v. 23, n. Especial, p. 77-100, jan./jan., 2021. Disponível em: https://doi.org/10.5007/1980-4512.2021.e78996. 


\title{
NOTAS
}

\section{TÍTULO DA OBRA}

EDUCAÇÃO INFANTIL EM TEMPOS DE PANDEMIA: OUTROS DESAFIOS PARA OS DIREITOS, AS POLÍTICAS E AS PEDAGOGIAS DAS INFÂNCIAS

Childhood Education in pandemic times: Other challenges for children's rights, policies and pedagogies

Cleriston Izidro dos Anjos

Centro de Educação

Universidade Federal de Alagoas Maceió, Alagoas, Brasil

cianjos@yahoo.com.br

Dhttps://orcid.org/0000-0003-1040-4909

Fábio Hoffmann Pereira

Campus Arapiraca

Universidade Federal de Alagoas

Arapiraca, Alagoas, Brasil

hoffmann@arapiraca.ufal.br

Dhttps://orcid.org/0000-0002-2933-2610

\section{Endereço de correspondência do principal autor}

Rua Governador Carlos Lacerda, 43, Apto. 404, Edf. Santa Maria, Jatiuca, CEP 57035-854, Maceió, AL, Brasil.

\begin{abstract}
AGRADECIMENTOS
Agradecemos ao público que vinha participando das atividades desenvolvidas pelo Grupo de Estudos e Pesquisas em Pedagogias e Culturas Infantis (GEPPECI/CNPq/UFAL), durante o primeiro ano da pandemia da Covid-19, trazendo questões, provocações e temáticas importantes para o debate e a construção do conhecimento. Agradecemos a contribuição de pesquisadoras/es, militantes de movimentos em defesa das infâncias e da Educação Infantil, professoras/es e demais profissionais da educação e todas/os as/os colaboradoras/es que gentilmente aceitaram participar das Lives do GEPPECI e do Webnário "Infâncias e Educação Infantil em tempos de pandemia", atividades que deram origem às ideias desta coletânea. Em especial, agradecemos às professoras Dra. Marina Rebeca de Oliveira Saraiva, Dra. Solange Estanislau dos Santos e Dra. Suzana Marcolino, todas vinculadas ao GEPPECI, que contribuíram imensamente na articulação com autoras e autores que aqui publicam. Agradecemos imensamente à Revista Zero-a-Seis, pela acolhida e compromisso com a divulgação do conhecimento científico de modo gratuito, aberto e livre e à Profa. Dra. Marcia Buss-Simão (UFSC, Brasil), pela partilha sempre solidária, afetiva, séria e responsável.
\end{abstract}

\section{CONTRIBUIÇÃO DE AUTORIA}

Concepção e elaboração do manuscrito: C. I. Anjos, F. H. Pereira

Coleta de dados: C. I. Anjos, F. H. Pereira

Análise de dados: C. I. Anjos, F. H. Pereira

Discussão dos resultados: C. I. Anjos, F. H. Pereira

Revisão e aprovação: C. I. Anjos, F. H. Pereira

\section{CONJUNTO DE DADOS DE PESQUISA}

O conjunto de dados que dá suporte aos resultados deste estudo não está disponível publicamente.

\section{FINANCIAMENTO}

A precarização do trabalho docente já vinha afetando os/as profissionais da Educação Básica e do Ensino Superior, da Educação Infantil à Pós-Graduação. No contexto de pandemia, essa situação tornou-se mais evidente com o trabalho remoto/domiciliar. Nesse sentido, é preciso deixar registrado que, nesse cenário, a situação se agravou com o aumento das despesas que temos arcado para a realização do trabalho docente que vem sendo realizado sem contrapartidas institucionais e governamentais: utilizamos nossos equipamentos, energia elétrica de nossas residências, nossa conexão de internet particular, nossos mobiliários e nossos espaços de convivência familiar. Se nós, professores e professoras, não realizássemos isso com recursos pessoais, a maior parte dos pesquisadores/as que publicam nesta coletânea e se unem 
a nós nesse tempo de pandemia, não teria tido condições de trabalhar para produzir este dossiê e tantos outros trabalhos. Fica, portanto, o registro de que a produção de conhecimento científico e o trabalho docente, necessitam de políticas públicas sérias e consistentes de valorização da carreira do magistério e de incentivo ao estudo e à pesquisa.

\section{CONSENTIMENTO DE USO DE IMAGEM}

Não se aplica.

\section{APROVAÇÃO DE COMITÊ DE ÉTICA EM PESQUISA}

Não se aplica.

\section{CONFLITO DE INTERESSES}

Não se aplica.

LICENÇA DE USO - uso exclusivo da revista

Os autores cedem à Zero-a-Seis os direitos exclusivos de primeira publicação, com o trabalho simultaneamente licenciado sob a Licença Creative Commons Attribution (CC BY) 4.0 International. Esta licença permite que terceiros remixem, adaptem e criem a partir do trabalho publicado, atribuindo o devido crédito de autoria e publicação inicial neste periódico. Os autores têm autorização para assumir contratos adicionais separadamente, para distribuição não exclusiva da versão do trabalho publicada neste periódico (ex.: publicar em repositório institucional, em site pessoal, publicar uma tradução, ou como capítulo de livro), com reconhecimento de autoria e publicação inicial neste periódico.

PUBLISHER - uso exclusivo da revista

Universidade Federal de Santa Catarina. Núcleo de Estudos e Pesquisas da Educação na Pequena Infância - NUPEIN/CED/UFSC. Publicação no Portal de Periódicos UFSC. As ideias expressadas neste artigo são de responsabilidade de seus autores, não representando, necessariamente, a opinião dos editores ou da universidade.

EDITORES - uso exclusivo da revista Márcia Buss-Simão e Kátia Agostinho.

HISTÓRICO - uso exclusivo da revista

Recebido em: 20-01-2021 - Aprovado em: 21-01-2021 